\title{
Role of Inflammation in Atrial Fibrillation Pathophysiology and Management
}

\author{
Masahide Harada, MD, PhD; David R. Van Wagoner, PhD; Stanley Nattel, MD
}

\begin{abstract}
Atrial fibrillation (AF) is the most common clinically relevant arrhythmia, but the methods available for treating AF and its complications (of which the most important is thrombogenesis), as well as for assessing AF risk and underlying pathophysiology, are largely limited. Emerging evidence suggests a significant role of inflammation in the pathogenesis of AF. That evidence includes elevated serum levels of inflammatory biomarkers in AF subjects, the expression of inflammatory markers in cardiac tissues of AF patients and animal models of AF, and beneficial effects of anti-inflammatory drugs in experimental AF paradigms. Inflammation is suggested to be linked to various pathological processes, such as oxidative stress, apoptosis, and fibrosis, that promote AF substrate formation. Inflammation has also been associated with endothelial dysfunction, platelet activation, and coagulation cascade activation, leading to thrombogenesis. Thus, inflammation may contribute to both the occurrence/maintenance of AF and its thromboembolic complications. Here, we review the evidence for a role of inflammation and inflammatory biomarkers in the risk management and treatment of AF. We also summarize the current knowledge of inflammationdependent cellular and molecular mechanisms in AF pathophysiology and their potential as therapeutic targets. (Circ J 2015; 79: 495-502)
\end{abstract}

Key Words: Anti-inflammatory drugs; Atrial fibrillation; Inflammatory markers; Thrombogenesis

A trial fibrillation (AF) is the most common clinical arrhythmia, and is associated with increased morbidity and mortality. However, the options for therapy and follow-up are largely limited. Emerging evidence points to a close relationship between inflammation and AF. ${ }^{1}$ The prevalence and prognosis of AF are both associated with serum levels of inflammatory biomarkers. ${ }^{1,2}$ Inflammatory infiltrates have been observed in atrial tissues from AF patients. ${ }^{3} \mathrm{AF}$ after cardiac surgery is associated with thoracotomy-induced pericarditis. ${ }^{4}$ Inflammation also contributes to a broad spectrum of cardiovascular diseases comorbid with $\mathrm{AF}$, including heart failure $(\mathrm{HF}),{ }^{5}$ coronary artery disease (CAD), ${ }^{6,7}$ and hypertension ${ }^{8}$ (Figure 1). ${ }^{9}$

Inflammation has been implicated in various AF-related pathological processes, including oxidative stress, fibrosis, and thrombogenesis (Figure 1).,10,11 However, the efficacy of antiinflammatory interventions for $\mathrm{AF}$ remains controversial, perhaps in part because the precise mechanistic links remain to be clarified. In addition, there are 2 critical unanswered questions: (1) whether inflammation associated with AF is a cause or a consequence of the arrhythmia, and (2) whether inflammation reflects underlying disease or AF itself. A better understanding is required in order to know whether inflammatory pathways can be exploited to improve strategies for AF management and prevention. Here, we will review the current evidence for the role of inflammation and inflammatory biomarkers in the risk management and treatment of AF. We will also discuss the evidence for inflammation-related cellular and molecular mechanisms of $\mathrm{AF}$ and their value as potential therapeutic targets.

\section{Inflammation-Related Heart Diseases and AF}

Inflammation has been implicated in the pathophysiology of various cardiac, as well as non-cardiac, diseases that are comorbid with AF.

HF and cardiomyopathy are associated with a 4-6-fold increase in AF prevalence. ${ }^{9}$ Inflammation has been implicated in the pathophysiology of HF and modulates the cell signaling activation patterns associated with fibrosis, apoptosis and hypertrophy; 5 these are all forms of cardiac remodeling that, when they occur at the atrial level, predispose to AF. For example, serum levels of tumor necrosis factor- $\alpha$ (TNF- $\alpha$ ), an inflammatory mediator, were significantly increased in diastolic HF patients with a history of $\mathrm{AF}$ in a community-based $\mathrm{HF}$ cohort. $^{12}$

CAD is a systemic, lipid-driven condition with immuneinflammatory components. ${ }^{6,7} \mathrm{AF}$ frequently occurs in acute

Received February 3, 2015; accepted February 4, 2015; released online February 16, 2015

Department of Cardiology, Fujita Health University School of Medicine, Toyoake (M.H.), Japan; Department of Molecular Cardiology, Cleveland Clinic, OH (D.R.V.W.), USA; and Department of Medicine and Research Center, Montreal Heart Institute and Université de Montréal, Montreal, Quebec (S.N.), Canada

Mailing address: Stanley Nattel, MD, Department of Medicine and Research Center, Montreal Heart Institute and Université de Montréal, Montreal, 5000 Belanger St. E., Montreal, Quebec H1T 1C8, Canada. E-mail: stanley.nattel@icm-mhi.org

ISSN-1346-9843 doi:10.1253/circj.CJ-15-0138

All rights are reserved to the Japanese Circulation Society. For permissions, please e-mail: cj@j-circ.or.jp 


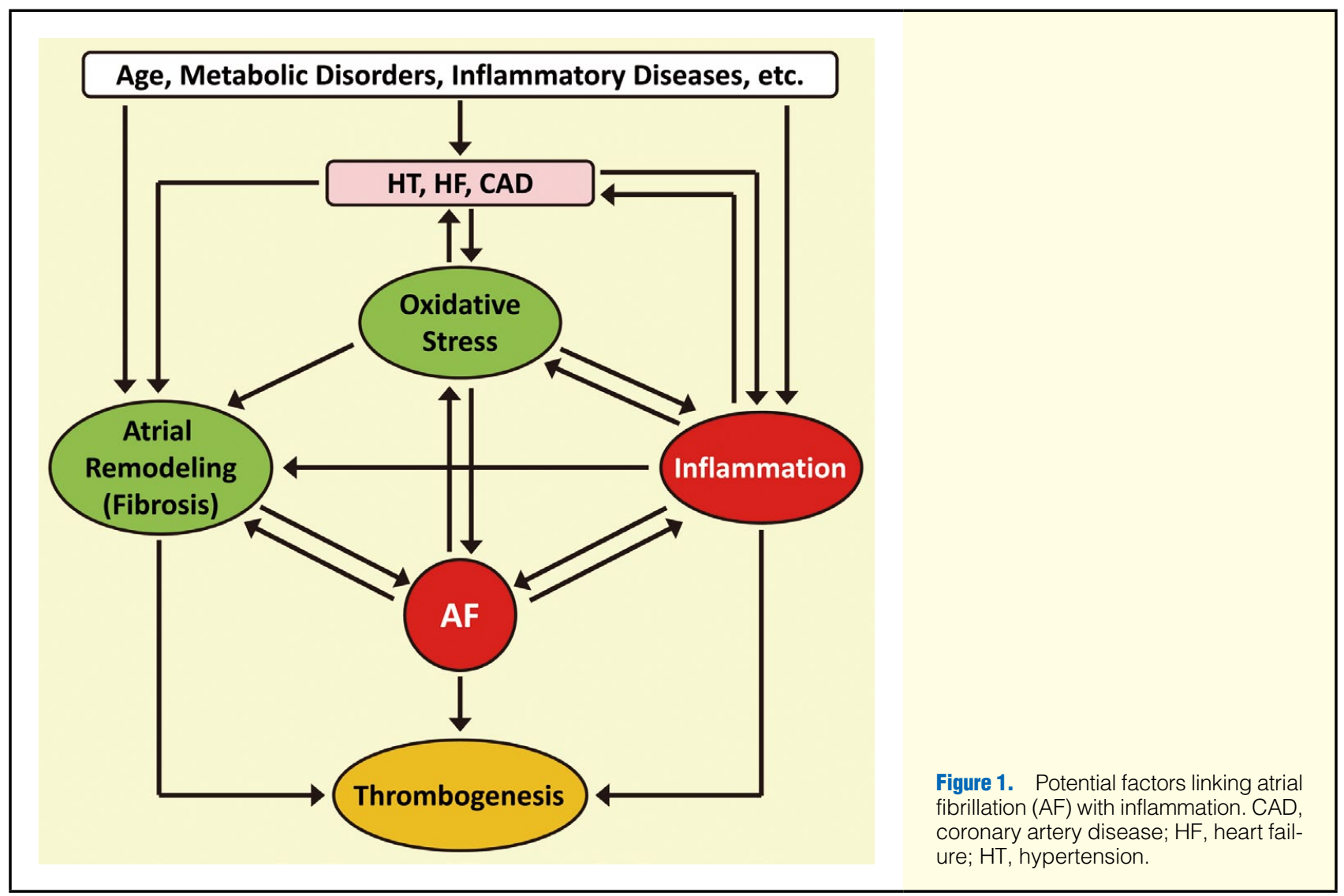

myocardial infarction, especially in the early stages when the myocardial inflammatory reaction is at its maximal. Serum levels of interleukin-6 (IL-6), an inflammatory biomarker, were independently associated with AF risk in a cohort of subjects with known CAD. ${ }^{13}$

Hypertension increases AF risk and is associated with systemic inflammation. ${ }^{8}$ A recent study from a group of Danish nationwide registries found that inflammatory bowel disease is associated with an increased incidence of AF and stroke. ${ }^{14}$ These observations suggest that systemic inflammation contributes to AF.

\section{Evidence for Inflammatory-Cell Recruitment in AF}

Migration of immune cells toward injured tissue is an important component of the inflammatory response. Leukocyte infiltration has been confirmed in the atrial tissue of AF subjects. ${ }^{3,15}$ Myeloperoxidase (MPO), an oxidizing agent secreted from infiltrating leukocytes, appears to play an important role in atrial fibrosis and AF development. ${ }^{16}$ AF patients undergoing cardiac bypass surgery had higher plasma MPO levels and larger MPO deposition in atrial tissue than sinus rhythm (SR) patients. ${ }^{16}$ MPO-knockout mice had attenuated atrial fibrosis and AF-promotion following chronic angiotensin-II infusion. ${ }^{16}$ In samples of the left atrial appendage, macrophage migration was greater in AF vs. SR patients, predominantly in the endoand subendocardium, together with deposition of adhesion molecules and inflammatory cytokines. ${ }^{17}$ In pressure-overloaded mice, atrial mast cell recruitment is responsible for atrial inflammation and fibrosis through a platelet-dependent growth factor-A-related mechanism. ${ }^{18}$

\section{Cellular and Molecular Mechanisms}

Rapid atrial activity that is not synchronized with the irregular ventricular response during AF increases atrial wall stress (stretch) and decreases cardiac output. Both hypoperfusion of hormone-regulatory organs and atrial stretch activate the renin-angiotensin-aldosterone system, producing angiotensin II. Altered hemodynamic rheology is associated with endothelial damage and recruitment of inflammatory cells that secrete cytokines. Figure 2 summarizes the principal inflammationrelated molecular mechanisms in $\mathrm{AF}$, which are discussed next in detail.

\section{Angiotensin II}

Angiotensin II activates NADPH oxidase, which produces reactive oxygen species (ROS). ROS can act as a second messenger to activate downstream effectors, but excess production can induce cellular oxidative stress. Angiotensin II and ROS contribute to abnormal $\mathrm{Ca}^{2+}$ handling and $\mathrm{Ca}^{2+}$ overload, which cause atrial hypocontractility and activate $\mathrm{Ca}^{2+}$-dependent signaling. ${ }^{19} \mathrm{Ca}^{2+}$-induced activation of nuclear factor of activated T-cells (NFAT) suppresses the gene expression of L-type calcium channel subunits, causing downregulation of the L-type $\mathrm{Ca}^{2+}$-current, decreased action potential duration and AFinduced electrical remodeling. ${ }^{20}$ In addition, NFAT downregulates the transcription of microRNA-26, disinhibiting the translation of Kir2.1 and TRPC3, resulting in electrical and fibrotic remodeling. ${ }^{20}$ Angiotensin II also activates the $S \operatorname{mad} 2 / 3$ axis, increasing the production of transforming growth factor- $\beta$ $(\mathrm{TGF}-\beta)$ and the extracellular matrix (ECM) proteins that form AF-promoting fibrous tissue. ${ }^{20}$ 


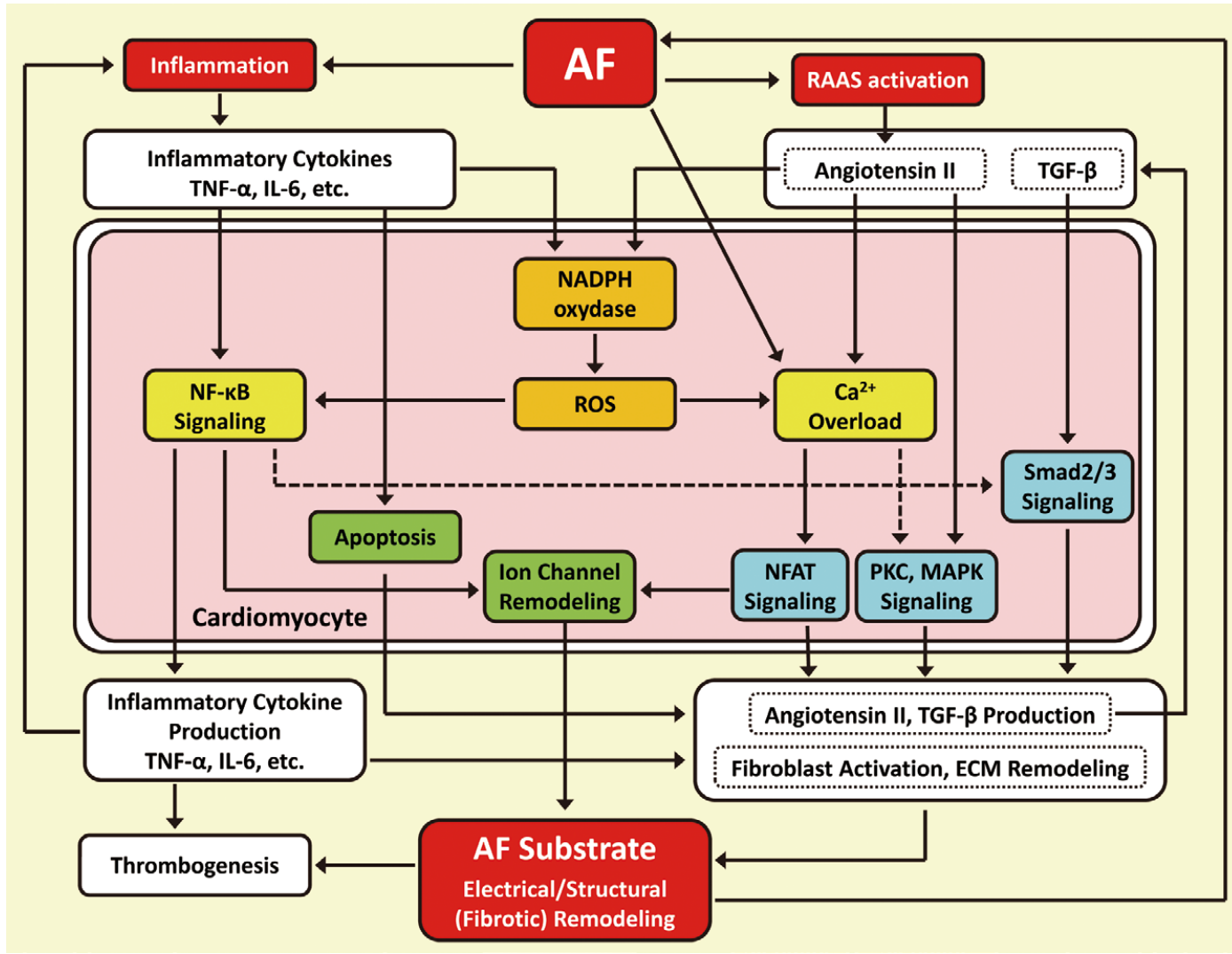

Figure 2. Inflammation-related cellular and molecular pathophysiology in atrial fibrillation (AF) progression. ECM, extracellular matrix; IL-6, interleukin-6; MAPK, mitogen-activated protein kinase; NFAT, nuclear factor of activated T-cells; NF-kB, nuclear factor $k$-light-chain-enhancer of activated B-cells; PKC, protein kinase C; RAAS, renin-angiotensin-aldosterone system; ROS, reactive oxygen species; Smad2/3, SMA- and MAD-related proteins, TGF- $\beta$, transforming growth factor- $\beta$; TNF- $\alpha$, tissue necrosis factor- $\alpha$.

\section{NF-kB and Inflammatory Cytokines}

Nuclear factor $\kappa$-light-chain-enhancer of activated B cells $(\mathrm{NF}$ $\kappa \mathrm{B})$, a transcription factor, is a crucial inflammatory signaling molecule. Both inflammatory cytokines and ROS activate $\mathrm{NF}-\kappa \mathrm{B} .{ }^{19}$ Nuclear translocation of activated NF- $\kappa \mathrm{B}$ increases the gene expression of inflammatory cytokines, exacerbating inflammation. ${ }^{21}$ Inflammatory cytokines enhance tissue factor (TF) production, promoting thrombogenesis. ${ }^{11}$ Inflammatory cytokines also induce apoptosis; ${ }^{21}$ apoptotic cardiomyocyte death is accompanied by fibroblast recruitment and ECM deposition, forming fibrosis. Inflammation and fibrosis are interrelated and potentially share common signaling cascades; TNF- $\alpha$ induces atrial fibrosis via activation of TGF- $\beta / \mathrm{Smad} 2 / 3$ signaling. ${ }^{22}$ TNF- $\alpha$ also regulates matrix metalloproteinase activity and ECM degradation. ${ }^{23} \mathrm{NF}-\kappa \mathrm{B}$ may also regulate the expression of $\mathrm{Na}^{+}$-channel subunits that contribute to AFassociated electrical remodeling. ${ }^{24}$

\section{Inflammatory Biomarkers and AF}

Many studies have examined blood levels of inflammatory biomarkers in $\mathrm{AF}$.

\section{C-Reactive Protein}

$\mathrm{C}$-reactive protein (CRP) is a highly reproducible but nonspe- cific inflammatory biomarker, synthesized primarily in the liver in response to inflammatory cytokines. The circulating level of CRP is increased in patients with AF compared with those without an AF history, and persistent-AF patients have higher CRP levels than do those with paroxysmal-AF. ${ }^{25}$ A Mendelian randomization study showed that although elevated CRP levels were associated with increased AF risk, genetically elevated CRP levels did not increase the risk, arguing against a causative effect of plasma CRP. ${ }^{26}$ Higher circulating CRP levels are also associated with AF recurrence after electrical cardioversion and catheter ablation. ${ }^{27,28}$

Stroke is a major complication of AF. An association between inflammation and stroke risk in AF patients has been reported; high-sensitivity CRP (hs-CRP) levels positively correlate with stroke risk factors (eg, diabetes and hypertension) in AF patients and are also related to mortality and a composite outcome of ischemic stroke, myocardial infarction, and vascular death. ${ }^{29,30}$

When interpreting the literature, it is important to note that most studies have involved measuring variables in a population, and then assessing their independent statistical associations with AF risk. Factors that are independently associated with AF are then described as "predictors" of AF risk. However, the predictive value of a risk factor must be established prospectively by testing its usefulness for estimating risk and 
guiding management in an independent population; unfortunately, this type of data is rarely available for putative AF biomarkers, because the appropriate studies have yet to be performed.

\section{Interleukin-6}

IL- 6 is produced by lymphocytes and stimulates inflammatory responses. IL-6 also has anti-inflammatory effects, via the inhibition of TNF- $\alpha$ signaling and the activation of IL-10, an anti-inflammatory cytokine.

A recent meta-analysis reported that higher IL- 6 blood levels were associated with greater AF risk in the general population. Greater serum IL-6 levels were also related to increased risks of AF recurrence after electrical cardioversion and catheter ablation. ${ }^{28}$ Conway et al demonstrated that high serum IL-6 levels were independently associated with stroke and the composite endpoint of stroke or death. ${ }^{31}$ Serum IL-6 levels were independently related to adverse events and mortality during long-term follow-up ( $>2$ years) in a large cohort of anticoagulated permanent/paroxysmal-AF patients. ${ }^{32}$

In a case-control study, Marcus et al demonstrated that serum CRP and IL-6 levels were similar in patients with vs. without previous AF episodes, but were significantly increased in blood samples taken during AF. ${ }^{33}$ Thus, AF may increase production of these acute-phase reactants, rather than the substances themselves increasing AF risk. CRP levels were greater in the left atrium than in the coronary sinus, suggesting that AF may cause sequestration of inflammatory reactants in the heart.

\section{TNF- $a$}

TNF- $\alpha$ stimulates an acute immune cell reaction and induces inflammation. TNF- $\alpha$ is synthesized by various immune cells, including macrophages and lymphocytes.

Li et al demonstrated that serum TNF- $\alpha$ blood levels were greater in patients with AF compared with those in SR, and in persistent and permanent $\mathrm{AF}$ compared with paroxysmal AF. ${ }^{34}$ A recent meta-analysis reported that higher $\mathrm{TNF}-\alpha$ levels were associated with greater AF risk. ${ }^{28}$ Higher TNF- $\alpha$ levels in chronic-AF patients on admission to hospital were also predictive of stroke risk during follow-up. ${ }^{35}$

\section{Interleukin-8}

IL-8 is produced by various types of cells, including macrophages, monocytes, fibroblasts, and endothelial cells. IL-8 promotes leukocyte migration and induces phagocytosis. IL-8 also enhances endothelial cell activation and modulates the platelet-platelet and platelet-leukocyte interactions associated with thrombogenesis.

Liuba et al demonstrated that serum IL-8 levels in the right atrium and coronary sinus, but not in the pulmonary veins, were greater in patients with permanent AF than in those with paroxysmal AF or SR. ${ }^{36}$ CRP and IL-6 levels were not different among the 3 groups.

\section{Interleukin-10}

IL-10 is an anti-inflammatory cytokine mainly produced by monocytes. IL-10 suppresses T-cell cytokines, enhances B-cell survival, proliferation, and antibody production, and blocks inflammatory signaling via NF- $\kappa \mathrm{B}$.

$\mathrm{Li}$ et al reported that serum IL-10 levels were greater in persistent and permanent $\mathrm{AF}$ patients compared with those having paroxysmal AF, as were levels of IL-6, IL-8, TNF- $\alpha$, monocyte chemoattractant protein-1 (MCP-1), vascular endothelial growth factor and $\mathrm{N}$-terminal pro-brain natriuretic peptide. ${ }^{34}$ The rhythm of patients at the time of sampling was not detailed, so it is unclear whether the differences were related to acute effects of AF or underlying inflammation/injury. Prior to cardioversion, AF patients had greater blood levels of CRP, TNF- $\alpha$, soluble intercellular adhesion molecule-1 (sICAM-1), malondialdehyde, and nitrotyrosine (NT) compared with the SR controls, and these levels were greater in patients with subsequent persistent-AF recurrence vs. those without. ${ }^{37}$ Successful SR maintenance was associated with faster decrease in IL-6, sICAM-1 and NT levels following cardioversion.

Others

MCP-1 is a chemokine that recruits monocytes into the arterial intima in atherosclerosis. Growth differentiation factor 15 (GDF-15) is a subfamily of TGF- $\beta$ associated with oxidative stress and inflammation. Circulating MCP-1 and GDF-15 levels have been associated with prognosis in patients with CAD and HF.1,38,39 GDF-15 blood levels were also independently associated with the risk of stroke, major bleeding, and death in AF patients on anticoagulation therapy. ${ }^{38}$ In contrast, MCP-1 has not been associated with AF risk. ${ }^{2}$

\section{Inflammation and Fibrosis in AF}

Atrial fibrosis is a major characteristic of AF-related remodeling. ${ }^{40}$ In atrial tissue from AF patients with valvular heart disease, there were significant positive correlations among NF- $\kappa$ B activity, serum TNF- $\alpha$ and IL-6 levels, and collagen volume fraction. ${ }^{41}$ Serum levels of the fibro-inflammatory biomarkers MMP-9, type III procollagen, and hs-CRP, were greater in persistent-AF patients than in SR controls, and positively correlated with echocardiographic left atrial volume, an index of atrial remodeling. ${ }^{42}$ After AF ablation, serum levels of some fibro-inflammatory biomarkers (hs-CRP and IL-6) decreased in patients without AF recurrence, whereas others (tissue inhibitor of metalloproteinase-2 (TIMP-2), matrix metalloproteinase-2 (MMP-2), carboxyl-terminal telopeptide of collagen type I) increased. ${ }^{43}$ Baseline MMP-2 levels were greater in those with recurrence. ${ }^{43}$ In a postmortem analysis, inflammatory macrophage markers and fibrosis colocalized in subendocardial atrial tissues of AF patients, consistent with an association between inflammation and fibrosis in $\mathrm{AF} .44$

\section{Inflammation and Postoperative AF (POAF)}

POAF occurs in $16-50 \%$ of patients after cardiac surgery. ${ }^{4}$ Greater perioperative serum levels of inflammatory biomarkers (CRP, IL-6, and IL-2) have been associated with the risk of POAF.,22 POAF usually occurs within the first few days after surgery, with the time course corresponding to changes in serum levels of inflammatory biomarkers. ${ }^{4}$ Treatment with several anti-inflammatory agents has been reported to reduce the prevalence of POAF. ${ }^{45}$

\section{Anti-Inflammatory Interventions in AF}

\section{Statins}

Statins have pleiotropic actions beyond cholesterol reduction, including improved endothelial function, reduced thrombogenesis, and suppression of oxidative stress and inflammation. In animal AF models, statins decreased AF vulnerability. ${ }^{46}$

Pena et al reported that patients with elevated CRP blood levels randomized to rosuvastatin treatment had significantly reduced AF risk vs. those randomized to placebo; ${ }^{47}$ however, meta-analyses have suggested that statins may not be effective 


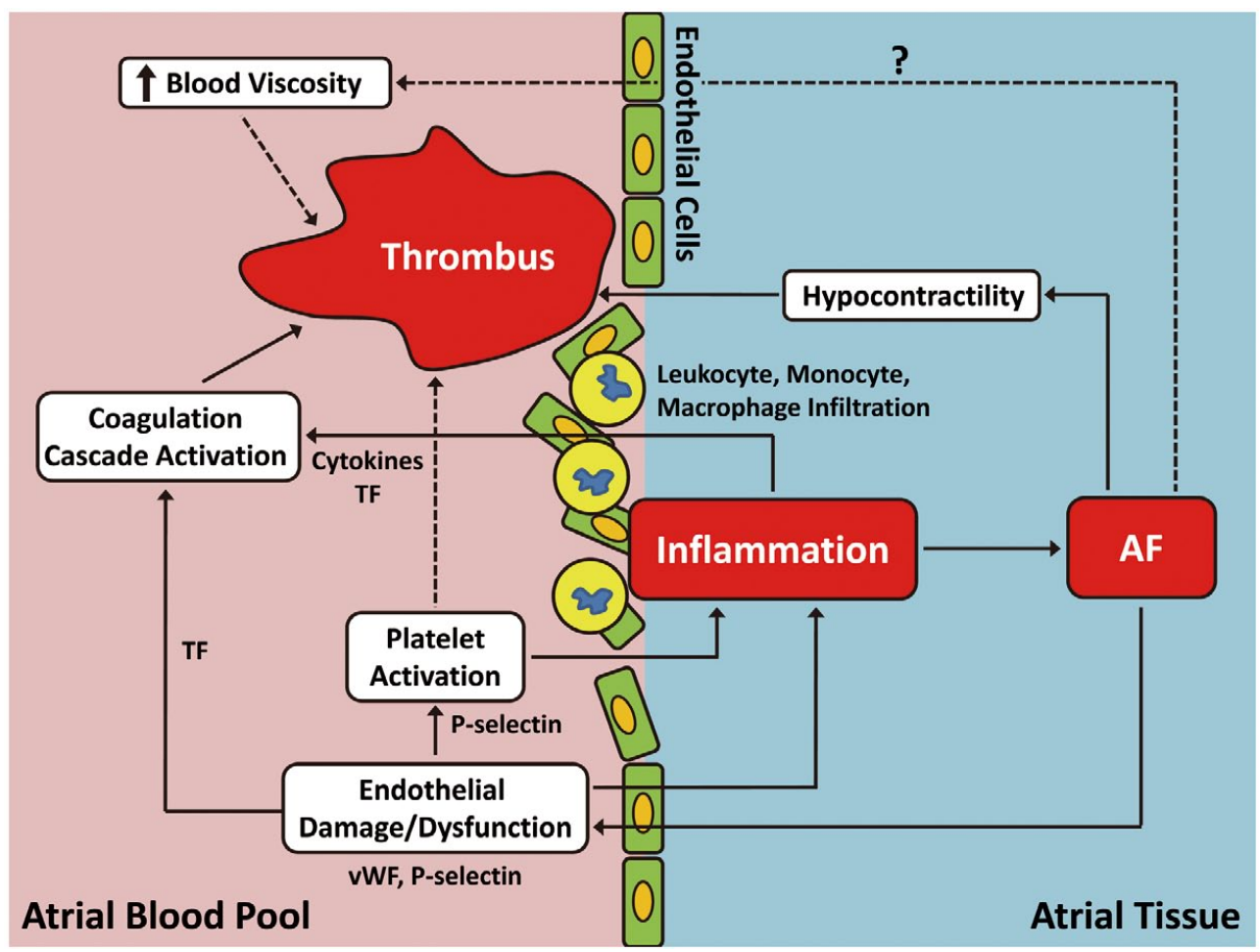

Figure 3. Potential mechanisms underlying thrombogenesis in atrial fibrillation (AF) and the role of inflammation. TF, tissue factor; vWF, von Willebrand factor.

for primary prevention of AF.48,49 Statins also failed to prevent $\mathrm{AF}$ recurrence after cardioversion ${ }^{47}$ and catheter ablation. ${ }^{50}$ Nevertheless, the perioperative use of statins has reduced POAF incidence, lowered serum inflammatory biomarkers, and attenuated reperfusion myocardial injury after cardiac surgery. ${ }^{4}$

\section{Corticosteroids}

In an experimental study, tachycardia-induced atrial remodeling and AF vulnerability were attenuated by prednisone treatment; circulating CRP levels were also decreased. ${ }^{51}$ Potential adverse effects such as hyperglycemia, infection, and gastrointestinal bleeding deter the routine use of corticosteroids in the clinical setting. Meta-analysis shows that corticosteroids reduce the risk of POAF and length of hospital stay without increased risk of infection. ${ }^{52}$ The dose-response curve is U-shaped, with intermediate doses (50-210 mg of dexamethasone equivalent) recommended. ${ }^{53}$ Intermediate-dose corticosteroids also decreased AF recurrence within 3 days after catheter ablation, ${ }^{54}$ but low-dose corticosteroids failed to prevent early AF recurrence. ${ }^{55}$

\section{Vitamins}

Vitamins $\mathrm{C}$ and $\mathrm{E}$ are safe, inexpensive and well-tolerated antioxidants. Vitamin $\mathrm{C}$ serum levels inversely correlated with the incidence of stroke in a Japanese population. ${ }^{56}$ Are vitamins $\mathrm{C}$ or $\mathrm{E}$ useful for treating or preventing AF? Carnes et al demonstrated that vitamin $\mathrm{C}$ attenuated $48 \mathrm{~h}$ of ATP-induced atrial remodeling and reduced ROS production in dogs, ${ }^{57}$ however, a longer (7 days) study found that antioxidant vitamins did not suppress ATP-induced atrial electrical remodeling in the same dog model. ${ }^{46} \mathrm{~A}$ meta-analysis reported that prophylactic use of vitamin $\mathrm{C}$ reduced the incidence of POAF after cardiac surgery, but the quality of available studies was limited. ${ }^{58} \mathrm{~A}$ combination of vitamins $\mathrm{C}$ and $\mathrm{E}$ and fish oils favorably reduced the occurrence of POAF.$^{59}$ In a small, non-blinded study, vitamin $\mathrm{C}$ decreased AF recurrence and inflammatory biomarker levels after electrical cardioversion. ${ }^{60}$ In spite of these reports, a broad analysis suggests limited utility of vitamin supplementation for prevention of either $\mathrm{AF}^{10}$ or cardiovascular disease in general.

\section{Polyunsaturated Fatty Acids}

Omega-3 (n-3)-PUFAs, such as eicosapentaenoic acid and docosahexaenoic acid, are abundant in fatty fish and have antiinflammatory and anti-oxidative effects. PUFAs decreased AF duration and atrial fibrosis in a canine HF model. ${ }^{61}$

The clinical efficacy of PUFAs for AF is questionable. High-dose PUFA treatment failed to prevent paroxysmal-AF recurrence. ${ }^{62} \mathrm{~A}$ meta-analysis demonstrated that short-term PUFA treatment did not decrease POAF risk. ${ }^{63}$

\section{Colchicine}

Colchicine suppresses leukocyte activation, endothelial cell adhesion and migration. Postoperatively-initiated adjusteddose colchicine prevented POAF and shortened hospital stay without significant adverse effects in a double-blind randomized trial. ${ }^{64}$ A subsequent study with preoperatively-initiated fixed-dose colchicine failed to show reduced POAF risk and colchicine treatment was associated with significant gastrointestinal side effects. ${ }^{65}$ 


\section{Inflammation and AF-Related Thrombogenesis}

AF-related thrombogenesis and inflammation are intimately linked (Figure 3). Serum CRP levels positively correlate with clinical risk factors for stroke. ${ }^{66}$ In AF patients, increased CRP levels are associated with left atrial thrombus formation and/ or dense spontaneous echo contrast. ${ }^{67}$ Inflammation has been implicated in multiple components leading to AF-related thrombogenesis: (1) endothelial damage/dysfunction, (2) platelet/ endothelial cell activation, and (3) coagulation cascade activation.

\section{Endothelial Damage and Dysfunction}

$\mathrm{AF}$ causes static and/or turbulent flow in the atrium that may induce endothelial damage and dysfunction. Atrial endothelial injury recruits cytokine-producing inflammatory cells, triggering inflammatory reactions. Flow-mediated dilation, a clinical indicator of endothelial integrity, decreases in AF patients. ${ }^{68}$ Flow-mediated dilation is inversely related to serum CRP levels in chronic-AF patients, implying disruption by inflammation. ${ }^{69}$ von Willebrand factor (vWF), an adhesion molecule, is an index of endothelial damage/dysfunction; plasma vWF levels positively correlate with AF incidence and stroke risk in the elderly population. ${ }^{70,71}$

\section{Platelet and Endothelial Cell Activation}

The loss of endothelial integrity accelerates the attachment of vWF onto the injured endothelium. Circulating platelets agglutinate with fibrinogen upon interaction with vWF. Platelet/endothelial cell interaction induces the expression of $\mathrm{P}$-selectin (an adhesion molecule). The P-selectin glycoprotein ligand-1 (PSGL-1) is expressed on the surface of leukocytes and monocytes; P-selectin binding to PSGL-1 promotes leukocyte/monocyte-endothelial cell attachment and interaction, producing a thrombo-inflammatory environment. The acute onset of AF induces endothelial dysfunction, platelet activation (platelet P-selectin expression), and inflammation in the human left atrium. ${ }^{72}$ Acutely-induced AF increases platelet $\mathrm{P}$-selectin expression, together with $\mathrm{P}$-selectin-positive monocytes/leucocytes and P-selectin/PSGL-1 double-positive monocytes. ${ }^{73}$ Catheter ablation and successful SR maintenance are reported to decrease platelet activation, improve endothelial function, and reduce levels of inflammation-associated markers in AF patients. ${ }^{74}$

Note that in AF a fibrin-rich thrombus (red clot) forms, which is more prone to recruiting inflammatory cells than platelet-rich thrombus (white clot). This may be one reason why antiplatelet therapies are less effective for the prevention of AF-related events than anticoagulation.

\section{Coagulation Cascade Activation}

Endothelial injury promotes TF release from subendocardial tissue. Exposure of blood vessels to TF initiates the coagulation cascade. Inflammation also enhances IL-6 and CRP-stimulated TF production by monocytes. ${ }^{75,76}$ Serum TF levels and stroke risk are independently associated with serum IL-6 levels in chronic-AF patients. ${ }^{23}$ Soluble CD40 ligand (sCD40L), a platelet-activated inflammatory marker, also stimulates $\mathrm{TF}$ production when it binds to its receptor CD40 on leukocytes. ${ }^{11}$ The sCD40L levels are increased in patients with AF. ${ }^{77}$

\section{Conclusions}

There is extensive evidence that inflammation contributes to the pathophysiology of AF, both directly and via AF- promoting cardiovascular conditions that have an inflammatory etiology. AF may be both a cause and a consequence of inflammation; the precise mechanistic links remain unclear. Several inflammatory biomarkers are associated with AF risk, but their practical value in guiding AF management is not well established. The clinical efficacy of anti-inflammatory drugs is limited. The pathophysiology underlying AF varies importantly among patients and thus individualized treatment approaches are likely necessary. Nevertheless, inflammation is a common pathological process in this multifactorial arrhythmia, and therefore presents interesting opportunities for therapeutic innovation. However, much more needs to be known in order for these opportunities to be realized.

\section{Acknowledgments}

The authors thank France Thériault for excellent assistance with this manuscript.

\section{Disclosures}

S.N. is supported by the Canadian Institutes of Health Research (grants 6957 and 44365) and the Heart and Stroke Foundation of Canada. D.R.V.W. is supported by a grant from the National Institutes of Health (1R01HL111314).

\section{References}

1. Guo Y, Lip GY, Apostolakis S. Inflammation in atrial fibrillation. $J$ Am Col Cardiol 2012; 60: 2263-2270.

2. Vilchez JA, Roldan V, Hernandez-Romero D, Valdes M, Lip GY, Marin F. Biomarkers in atrial fibrillation: An overview. Int J Clin Pract 2014; 68: $434-443$.

3. Frustaci A, Chimenti C, Bellocci F, Morgante E, Russo MA, Maseri A. Histological substrate of atrial biopsies in patients with lone atrial fibrillation. Circulation 1997; 96: 1180-1184.

4. Maesen B, Maessen JN, Allessie M, Schotten U. Post-operative atrial fibrillation: A maze of mechanisms. Europace 2012; 14: 159-174.

5. Hofmann U, Frantz S. How can we cure a heart "in flame"? A translational view on inflammation in heart failure. Basic Res Cardiol 2013; 108: 356.

6. Libby P, Tabas I, Fredman G, Fisher EA. Inflammation and its resolution as determinants of acute coronary syndromes. Circ Res 2014; 114: $1867-1879$.

7. Duchatelle V, Kritikou EA, Tardif JC. Clinical value of drugs targeting inflammation for the management of coronary artery disease. Can J Cardiol 2012; 28: 678-686.

8. Schiffrin EL. The immune system: Role in hypertension. Can J Cardiol 2013; 29: $543-548$

9. Andrade J, Khairy P, Dobrev D, Nattel S. The clinical profile and pathophysiology of atrial fibrillation relationship among clinical features, epidemiology, and mechanisms. Circ Res 2014; 114: $1453-1468$.

10. Van Wagoner DR. Oxidative stress and inflammation in atrial fibrillation: Role in pathogenesis and potential as a therapeutic target. $J$ Cardiovasc Pharmacol 2008; 52: 306-313.

11. Watson T, Shantsila E, Lip GY. Mechanisms of thrombogenesis in atrial fibrillation: Virchow's triad revisited. Lancet 2009; 373: 155 166.

12. Putko BN, Wang Z, Lo J, Anderson T, Becher H, Dyck JRB, et al. Circulating levels of tumor necrosis factor-alpha receptor 2 are increased in heart failure with preserved ejection fraction relative to heart failure with reduced ejection fraction: Evidence for a divergence in pathophysiology. PLoS One 2014; 9: e99495, doi:10.1371/ journal.pone.0099495.

13. Marcus GM, Whooley MA, Glidden DV, Pawlikowska L, Zaroff JG, Olgin JE. Interleukin-6 and atrial fibrillation in patients with coronary artery disease: Data from the Heart and Soul Study. Am Heart J 2008; 155: 303-309.

14. Kristensen SL, Lindhardsen J, Ahlehoff O, Lamberts M, Khalid U, Torp-pedersen C, et al. Increased risk of atrial fibrillation and stroke during active stage of inflammatory bowel disease: A nationwide study. Europace 2014; 16: 477-484.

15. Chen MC, Chang JP, Liu WH, Yang CH, Chen YL, Tsai TH, et al. Increased inflammatory cell infiltration in the atrial myocardium of patients with atrial fibrillation. Am J Cardiol 2008; 102: 861-865.

16. Rudolph V, Andrié RP, Rudolph TK, Friedrichs K, Klinke A, 
Hirsch-Hoffmann B, et al. Myeloperoxidase acts as a profibrotic mediator of atrial fibrillation. Nat Med 2010; 16: 470-474.

17. Yamashita T, Sekiguchi A, Iwasaki YK, Date T, Sagara K, Tanabe $\mathrm{H}$, et al. Recruitment of immune cells across atrial endocardium in human atrial fibrillation. Circ J 2010; 74: 262-270.

18. Liao C, Akazawa H, Tamagawa M, Ito K, Yasuda N, Kudo Y, et al. Cardiac mast cells cause atrial fibrillation through PDGF-A-mediated fibrosis in pressure-overloaded mouse hearts. J Clin Invest 2010; 120: $242-253$.

19. Youn JY, Zhang J, Zhang Y, Chen H, Liu D, Ping P, et al. Oxidative stress in atrial fibrillation: An emerging role of NADPH oxidase. $J$ Mol Cell Cardiol 2013; 62: 72-79.

20. Nattel S, Harada M. Atrial remodeling and atrial fibrillation: Mechanisms and implications. J Am Coll Cardiol 2014; 63: 2335-2345.

21. Gordon JW, Shaw JA, Kirshenbaum LA. Multiple facets of NF- $\kappa$ B in the heart: To be or not to be NF- $\kappa$ B. Circ Res 2011; 108: 1122 1132.

22. Liew R, Khairunnisa K, Gu Y, Tee N, Yin NO, Naylynn TM, et al. Role of tumor necrosis factor-alpha in the pathogenesis of atrial fibrosis and development of an arrhythmogenic substrate. Circ J 2013; 77: 1171-1179.

23. Cao H, Wang J, Xi L, Roe OD, Chen Y, Wang D. Dysregulated atrial gene expression of osteoprotegerin/receptor activator of nuclear factor- $\kappa \mathrm{B}$ (RANK)/RANK ligand axis in the development and progression of atrial fibrillation. Circ J 2011; 75: 2781-2788

24. Shang LL, Sanyal S, Pfahnl AE, Jiao Z, Allen J, Liu H, et al. NF- $\kappa$ Bdependent transcriptional regulation of the cardiac SCN5a sodium channel by angiotensin. Am J Physiol Cell Physiol 2008; 294: C372-C379.

25. Chung MK, Martin DO, Sprecher D, Wazni O, Kanderian A, Cames $\mathrm{CA}$, et al. C-reactive protein elevation in patients with atrial arrhythmias: Inflammatory mechanisms and persistence of atrial fibrillation. Circulation 2001; 104: 2886-2891.

26. Marott SC, Nordestgaard BG, Zacho J, Friberg J, Jensen GB, Tybjaerg-Hansen A, et al. Does elevated C-reactive protein increase atrial fibrillation risk?: A Mendelian randomization of 47000 individuals from the general population. J Am Coll Cardiol 2010; 56: 789-795.

27. Watanabe E, Arakawa T, Uchiyama T, Kodama I, Hishida H. Highsensitive C-reactive protein is predictive of successful cardioversion for atrial fibrillation and maintenance of sinus rhythm after conversion. Int J Cardiol 2006; 108: 346-353.

28. Wu N, Xiang Y, Wu L, Zhang Y, Ma X, Tong S, et al. Association of inflammatory factors with occurrence and recurrence of atrial fibrillation: A meta-analysis. Int J Cardiol 2013; 169: 62-72.

29. Conway DS, Buggins P, Hughes E, Lip GY. Relationship of interleukin-6 and C-reactive protein to the prothrombotic state in chronic atrial fibrillation. J Am Coll Cardiol 2004; 148: 462-466.

30. Hermida J, Lopez FL, Montes R, Matsushita K, Astor BC, Alonso A. Usefulness of high-sensitivity C-reactive protein to predict mortality in patients with atrial fibrillation. Am J Cardiol 2012; 109: 95-99.

31. Conway DS, Buggins P, Hughes E, Lip GY. Prognostic significance of raised plasma levels of interleukin-6 and C-reactive protein in atrial fibrillation. Am Heart J 2004; 148: 462-466.

32. Roldan V, Marin F, Diaz J, Gallego P, Jover E, Romera M, et al High sensitivity cardiac troponin T and interleukin- 6 predict adverse cardiovascular events and mortality in anticoagulated patients with atrial fibrillation. J Thromb Haemost 2012; 10: 1500-1507.

33. Marcus GM, Smith LM, Ordovas K, Scheinman MM, Kim AM, Badhawar N, et al. Intra and extracardiac markers of inflammation during atrial fibrillation. Heart Rhythm 2010; 7: 149-154.

34. Li J, Solus J, Chen Q, Rho YH, Milne G, Stein CM, et al. The role of inflammation and oxidative stress in atrial fibrillation. Heart Rhythm 2010; 7: 438-444.

35. Pinto A, Tuttolomondo A, Casuccio A, Raimondo DD, Sciacca RD, Arnao V, et al. Immuno-inflammatory predictors of stroke at followup in patients with chronic non-valvular atrial fibrillation. Clin Sci 2009; 116: 781-789.

36. Liuba I, Ahlmroth H, Jonasson L, Englund A, Jonsson A, Safstrom $\mathrm{K}$, et al. Source of inflammatory markers in patients with atrial fibrillation. Europace 2008; 10: 848 -853.

37. Leftheriotis DI, Fountoulaki KT, Flevari PG, Parissis JT, Panou FK, Andreadou IT, et al. The predictive value of inflammatory and oxydative markers following the successful cardioversion of persistent lone atrial fibrillation. Int J Cardiol 2009; 135: 361-369.

38. Wallentin L, Hijazi Z, Andersson U, Alexander JH, De Caterina R, Hanna M, et al; ARISTOTLE Investigators. Growth differentiation factor 15, a marker of oxidative stress and inflammation, for risk assessment in patients with atrial fibrillation: Insights from the Apix- aban for Reduction in Stroke and Other Thromboembolic Events in Atrial Fibrillation (ARISTOTLE) trial. Circulation 2014; 130: $1847-1858$

39. Izumiya $Y$, Hanatani $S$, Kimura $Y$, Yamamoto E, Kusaka H, Tokitsu $\mathrm{T}$, et al. Growth differentiation factor-15 is a useful prognostic marker in patients with heart failure with preserved ejection fraction. Can J Cardiol 2014; 30: 338-344.

40. Burstein B, Nattel S. Atrial fibrosis: Mechanisms and clinical relevance in atrial fibrillation. J Am Coll Cardiol 2008; 51: 802-809.

41. Qu YC, Du YM, Wu SL, Chen QX, Wu HL, Zhou SF. Activated nuclear factor-kappaB and increased tumor necrosis factor-alpha in atrial tissue of atrial fibrillation. Scand Cardiovasc J 2009; 43: $292-297$.

42. Sonmez O, Ertem FU, Vatankulu MA, Erdogan E, Tasal A, Kucukbuzcu S, et al. Novel fibro-inflammation markers in assessing left atrial remodeling in non-valvular atrial fibrillation. Med Sci Monit 2014; 20: $463-470$.

43. Okumura Y, Watanabe I, Nakai T, Ohkubo K, Kofune T, Kofune M, et al. Impact of biomarkers of inflammation and extracellular matrix turnover on the outcome of atrial fibrillation ablation: Importance of matrix metalloproteinase- 2 as a predictor of atrial fibrillation recurrence. J Cardiovasc Electrophysiol 2011; 22: 987-993.

44. Ito K, Date T, Ikegami M, Hongo K, Fujisaki M, Katoh D, et al. An immunohistochemical analysis of tissue thrombin expression in the human atria. PLoS One 2013; 8: e65817, doi:10.1371/journal.pone. 0065817.

45. Jacob KA, Nathoe HM, Deleman JM, Osch DV, Kluin J, Dijik DV Inflammation in new-onset atrial fibrillation after cardiac surgery: A systematic review. Eur J Clin Invest 2014; 44: 402-428.

46. Shiroshita-Takeshita A, Schram G, Lavoie J, Nattel S. The effect of simvastatin and antioxidant vitamins on atrial fibrillation-promotion by atrial tachycardia remodeling in dogs. Circulation 2004; 110: 2313-2319.

47. Pena JM, MacFadyen J, Glynn RJ, Ridker PM. High-sensitivity C-reactive protein, statin therapy, and risks of atrial fibrillation: An exploratory analysis of the JUPITER trial. Eur Heart J 2012; 33: 531-537.

48. Rahimi K, Emberson J, McGale P, Majoni W, Merhi A, Asselbergs FW, et al. Effect of statins on atrial fibrillation: Collaborative metaanalysis of published and unpublished evidence from randomized controlled trials. BMJ 2011; 342: d11250.

49. Bang CN, Greve AM, Abdulla J, Kober L, Gislason GH, Wachtell $\mathrm{K}$. The preventive effect of statin therapy on new-onset and recurrent atrial fibrillation in patients not undergoing invasive cardiac interventions: A systematic review and meta-analysis. Int J Cardiol 2013; 167: $624-630$.

50. Suleiman M, Koestler C, Lerman A, Lopez-Jimenez F, Herges R, Hodge D, et al. Atorvastatin for prevention of atrial fibrillation recurrence following pulmonary vein isolation: A double-blind, placebocontrolled, randomized trial. Heart Rhythm 2012; 9: 172-178.

51. Shiroshita-Takeshita A, Brundel BJ, Lavoie J, Nattel S. Prednisone prevents atrial fibrillation promotion by atrial tachycardia remodeling in dogs. Cardiovasc Res 2006; 69: 865-875.

52. Ho KM, Tan JA. Benefits and risk of corticosteroid prophylaxis in adult cardiac surgery: A dose-response meta-analysis. Circulation 2009; 119: $1853-1866$

53. Baker WL, White CM, Kluger J, Denowitz A, Konecny CP, Coleman Cl. Effect of perioperative corticosteroids use on the incidence of postcardiothoracic surgery atrial fibrillation and length of stay. Heart Rhythm 2007; 4: $461-468$.

54. Koyama T, Tada H, Sekiguchi Y, Arimoto T, Yamazaki H, Kuroki $\mathrm{K}$, et al. Prevention of atrial fibrillation recurrence with corticosteroids after radiofrequency catheter ablation. J Am Col Cardiol 2010; 56: $1463-1472$

55. Won H, Kim JY, Shim J, Uhm JS, Pak HN, Lee MH, et al. Effect of a single bolus injection of low-dose hydrocortisone for prevention of atrial fibrillation recurrence after radiofrequency catheter ablation. Circ J 2013; 77: 53-59.

56. Yokoyama T, Date C, Kokubo Y, Yoshiike N, Matsumura Y, Tanaka $\mathrm{H}$. Serum vitamin C concentration was inversely associated with subsequent 20-year incidence of stroke in a Japanese rural community: The Shibata study. Stroke 2000; 31: 2287-2294.

57. Carnes CA, Chung MK, Nakayama T, Nakayama H, Baliga RS, Piao $\mathrm{S}$, et al. Ascorbate attenuates atrial pacing-induced peroxynitrite formation and electrical remodeling and decreases the incidence of postoperative atrial fibrillation. Circ Res 2001; 89: E32-E38.

58. Harling L, Rasoli S, Vecht JA, Ashrafian H, Kourliouros A, Athanasiou T. Do antioxidant vitamins have an anti-arrhythmic effect following cardiac surgery? A meta-analysis of randomised controlled trials. Heart 2011; 97: 1636-1642. 
59. Rodrigo R, Korantzopoulos P, Cereceda M, Asenjo R, Zamorano J, Villalabeitia E, et al. A randomized controlled trial to prevent postoperative atrial fibrillation by antioxidant reinforcement. J Am Coll Cardiol 2013; 62: 1457-1465.

60. Korantzopoulos P, Kolettis TM, Kountouris E, Dimitroula V, Karanikis $\mathrm{P}$, Pappa E, et al. Oral vitamin C administration reduces early recurrence rates after electrical cardioversion of persistent atrial fibrillation and attenuates associated inflammation. Int J Cardiol 2005; 102: $321-326$

61. Sakabe M, Shiroshita-Takeshita A, Maguy A, Dumesnil C, Nigam A, Leung TK, et al. Omega-3 polyunsaturated fatty acids prevent atrial fibrillation associated with heart failure but not atrial tachycardia remodeling. Circulation 2007; 116: 2101-2109.

62. Nigam A, Talajic M, Roy D, Nattel S, Lambert J, Nozza A, et al; AFFORD Investigators. Fish oil for the reduction of atrial fibrillation recurrence, inflammation, and oxidative stress. J Am Coll Cardiol 2014; 64: $1441-1448$.

63. Mozaffarian D, Wu JH, de Oliveira Otto MC, Sandesara CM, Metcalf RG, Latini R, et al. Fish oil and post-operative atrial fibrillation: A meta-analysis of randomized controlled trials. J Am Coll Cardiol 2013; 61: 2194-2196.

64. Imazio M, Brucato A, Ferrazzi P, Rovere ME, Gandino A, Cemin R, et al; COPPS Investigators. Colchicine reduces postoperative atrial fibrillation: Results of the Colchicine for the Prevention of the Postpericardiotomy Syndrome (COPPS) atrial fibrillation substudy. Circulation 2011; 124: 2290-2295.

65. Imazio M, Brucato A, Ferrazzi P, Pullara A, Adler Y, Barosi A, et al; COPPS-2 Investigators. Colchicine for prevention of postpericardiotomy syndrome and postoperative atrial fibrillation: The COPPS-2 randomized clinical trial. JAMA 2014; 312: 1016-1023.

66. Thambidorai SK, Parakh K, Martin DO. Relation of C-reactive protein correlates with risk of thromboembolism in patients with atrial fibrillation. Am J Cardiol 2004; 94: 805-807.

67. Cianfrocca C, Loricchio ML, Pelliccia F, Pasceri V, Auriti A, Bianconi L, et al. C-reactive protein and left atrial appendage velocity are independent determinants of the risk of thrombogenesis in patients with atrial fibrillation. Int J Cardiol 2010; 142: 22-28.
68. Shin SY, Na JO, Lim HE, Choi CU, Choi JI, Kim SH, et al. Improved endothelial function in patients with atrial fibrillation through maintenance of sinus rhythm by successful catheter ablation. J Cardiovasc Electrophysiol 2011; 22: 376-382.

69. Tousoulis D, Zisimos K, Antoniades C, Stefanadi E, Siasos G, Tsioufis $\mathrm{C}$, et al. Oxidative stress and inflammatory process in patients with atrial fibrillation: The role of left atrium distention. Int J Cardiol 2009; 136: 258-262.

70. Wieberdink RG, van Schie MC, Koudstaal PJ, Hofman A, Witteman JC, de Maat MP, et al. High von Willebrand factor levels increase the risk of stroke: The Rotterdam study. Stroke 2010; 41: $2151-$ 2156.

71. Conway DS, Heeringa J, Van Der Kuip DA, Chin BS, Hofman A, Witteman JC, et al. Atrial fibrillation and the prothrombotic state in the elderly: The Rotterdam Study. Stroke 2003; 34: 413-417.

72. Lim HS, Willoughby SR, Schultz C, Gan C, Alasady M, Lau DH, et al. Effect of atrial fibrillation on atrial thrombogenesis in humans: Impact of rate and rhythm. J Am Coll Cardiol 2013; 61: 852-860.

73. Hayashi M, Takeshita K, Inden Y, Ishii H, Cheng XW, Yamamoto $\mathrm{K}$, et al. Platelet activation and induction of tissue factor in acute and chronic atrial fibrillation: Involvement of mononuclear cellplatelet interaction. Thromb Res 2011; 128: e113-e118, doi:10.1016/ j.thromres.2011.07.013.

74. Lim HS, Willoughby SR, Schultz C, Chakrabarty A, Alasady M, Lau $\mathrm{DH}$, et al. Successful catheter ablation decreases platelet activation and improves endothelial function in patients with atrial fibrillation. Heart Rhythm 2014; 11: 1912-1918.

75. Cermak J, Key NS, Bach RR, Balla J, Jacob HS, Vercellotti GM. C-reactive protein induces human peripheral blood monocytes to synthesize tissue factor. Blood 1993; 82: $513-520$.

76. Neumann FJ, Ott I, Matx N, Luther T, Gawaz M, Kotzsch M, et al. Effect of human recombinant interleukin-6 and interleukin-8 on monocyte procoagulant activity. Arterioscler Thromb Vasc Biol 1997; 17: 3399-3405.

77. Pamukcu B, Lip GY, Snezhitskiy V, Shantsila E. The CD40-CD40L system in cardiovascular disease. Ann Med 2011; 43: 331-340. 